\title{
The risks of cannabis and other illicit drugs: Views among French and Finnish addiction treatment providers
}

\author{
Laurence Simmat-Durand $^{1}$ and Anja Koski-Jännes ${ }^{2}$ \\ ${ }^{1}$ University Paris Descartes, INSERM U988, UMR 8211, 75006 Paris, France \\ ${ }^{2}$ School of Social Sciences and Humanities, University of Tampere, Finland
}

\begin{abstract}
Aims: This study explores the effect of cultural context and group-level factors on the views held by treatment professionals in France and Finland about addiction and the dangers of illicit drugs.

Design: Cross-cultural survey.

Setting: Similar questionnaires were mailed to professionals working in specialized addiction treatment units in both countries.

Participants: In Finland, 520 treatment providers working personally with clients responded, and 472 responded in France. The samples differed in several ways. Most notably, the medical profession was more dominant in France, while social work and counselling dominated in Finland.
\end{abstract}

Measures: In addition to demographics, the questions covered different addictions, and included questions on the levels of danger of heroin, amphetamines and cannabis for individuals and the society.

Findings: Consistent cultural differences appeared in the views of Finnish and French professionals regarding the addictiveness of illicit drugs and their level of danger to society. These differences remained significant after controlling for professions and other background variables.

Conclusions: Cultural context, local prevalence of high-risk behaviors, familiarity with the substance, country of residence, and level of education appeared as major modifiers of risk perceptions.

Although they may induce pleasure, psychoactive substances do great harm to individuals and society. Several experts have conducted assessments to rate the relative dangerousness of different drugs (Ezzati et al., 2002; Nutt, King, \& Phillips, 2010; Nutt, King, Saullsbury, \& Blakemore, 2007; Room, 2006; van Amsterdam, Opperhuizen, Koeter, \& van den Brink, 2010). A recent example is the multi-criteria assessment of the dangerousness of 20 drugs to individuals and society conducted in the U.K. by Nutt et al. (2010). The survey found that overall the most harmful drugs were alcohol, heroin, cocaine, amphetamines, tobacco and cannabis. Another expert assessment, in France, also considered the perceived benefits of drugs (Bourgain et al., 2012). Drug harms appeared rather similar to those found by Nutt \& al. (2010), but the inclusion of perceived benefits changed the overall result; for example, the perceived benefits of alcohol and tobacco far outweighed their harmfulness.
Our study focuses on the perceived dangerousness of drugs. The informants are addiction treatment professionals in two European countries. This choice of study subjects was motivated by the treatment professionals' vital intermediary role between the scientists and experts and the people needing treatment. Their opinions on drugs and addictive behavior influence the manner in which they handle the problem and the people they have to help (Brener, von Hippel, von Hippel, Resnick, \& Treolar, 2010; Christie \& Bruun, 1986; De los Reyes, 2002; Orford \& McCartney, 1990). As their work with substance abusers is informed by international research on psychoactive substances, it is probably assumed that professionals in most European countries share similar views on the relative dangerousness of these drugs. Yet, as noted by Bourgain et al. (2012), besides their knowledge of the objective costs of addiction, treatment professionals' culture, history and personal experiences may modify their views about psychoactive substances. 
Consideration of these factors is important in determining how the results of science are translated into professional practice. The purpose of this study is therefore to explore the role of cultural and other contextual factors in shaping the views of Finnish and French addiction treatment professionals on the dangerousness of drugs. We chose to concentrate on heroin, amphetamines and cannabis. Although these drugs are illicit in both countries, the extent of their use among the population (aged 15 to 64) differs. The annual prevalence figures for cannabis were $8.4 \%$ in France and $4.6 \%$ in Finland, for amphetamines $0.2 \%$ and $0.8 \%$, and for opioids $0.59 \%$ and $0.20 \%$, respectively (EMCDDA, 2012; UNODC, 2012). Among clients entering treatment for drug problems, $47.8 \%$ used cannabis, $0.3 \%$ amphetamines, and $40.7 \%$ opioids as their primary drug in France, compared with $13.4 \%, 14.1 \%$ and $62.2 \%$ in Finland (EMCDDA, 2012). The high percentage of opioid users among Finnish clients was due to the mostly illegal use of Subutex (high buprenorphine), which has totally replaced the previously more popular heroin. Despite the generally higher drug use in France, the drug-related mortality rate per million inhabitants was nearly seven times higher in Finland, mainly due to their widespread injection and polydrug use (Ibid.)

The treatment systems also differ. In France, the treatment providers are mostly medical doctors assisted by nurses, social workers and psychologists, whereas in Finland, most of them are social workers, counselors and nurses, with only a few physicians. The use of medication in treatment is much more common in France than in Finland. For instance, French general practitioners can prescribe Subutex, while in Finland it is only available to carefully chosen clients. So, in proportion to the populations, there are six times more clients in substitution treatment in France (EMCDDA, 2012).

\section{Theoretical Underpinnings and Previous Research}

Several theories about risk perception have emerged (Douglas \& Wildavsky, 1982; Slovic, 1987; Tversky \& Kahneman, 1974). The main conclusion is that risks are not perceived simply on the basis of objective prevalence statistics or probabilities, but on psychological, social and cultural factors too (Wilkinson, 2001). These include the perceivers' worldviews (Douglas \& Wildavsky, 1982), media influences, and such parameters as the object's voluntariness, naturalness, controllability, and familiarity (Slovic, 1987). The social representations approach (Moscovici, 1988), which also serves as our theoretical background, focuses more on the contextual and grouplevel factors in risk perception. Worries about risks are motivated by the protection of in-group and self-identity, and representations of risks are mainly formed to defend against the feelings of threat (Joffe, 2003).

Previous surveys on professionals' views on addiction have mostly been group comparisons in one country (Grassman \& Weisner, 2005; Luquiens, Reynaud, Aubin, Talon, \& Bourgain, 2013; Samuelsson, Blomqvist, \& Christophs, 2013). The Swedish survey by Samuelsson et al. (2013) compared the views of three groups of addiction treatment professionals regarding nine addictions. Heroin and amphetamines were considered highly dangerous for society, highly addictive and difficult to overcome. Tobacco products were placed on the opposite end of the spectrum, and cannabis, together with alcohol, gambling and medical drugs, in between. Profession, gender and education produced some differences. The results resembled those of the similar general population survey in Sweden, indicating that the risks of familiar addictions are downplayed, whereas the risks of uncommon addictive behaviors are overstated (Blomqvist, 2009; Blomqvist, Koski-Jännes, \& Cunningham, 2014).

When the same surveys were conducted in Finland (Blomqvist et al., 2014; Hirschovits-Gertz, 2013; Hirschovits-Gerz et al., 2011; Koski-Jännes, HirschovitsGerz, \& Pennonen, 2012), the results were largely similar, but the Finnish professionals seemed to regard the risk of dependence on all illicit drugs, particularly amphetamines, as higher than did those in Sweden. However, the risks of familiar addictions were not always downplayed. Personal familiarity with their harmful consequences also increased risk awareness. The socio-demographic variables that produced group differences in Finland were largely similar to those in Sweden: gender, occupation, professional education and personal addiction experiences (KoskiJännes et al., 2012; Pennonen \& Koski-Jännes, 2010).

Two cross-cultural studies compared the general population's views on addictions in Sweden, Finland, Canada and St. Petersburg, Russia (Blomqvist et al., 2014; Holma et al., 2011) and in two more studies comparisons involved the three first mentioned (Blomqvist et al., 2014; Cunningham et al., 2012). They displayed significant cultural differences in lay views on addictions. Professional views on addictions have been shown to be largely in line with lay views in each country (KoskiJännes et al., 2012; Samuelsson et al., 2013). It is therefore probable that significant cultural differences will also appear in the study at hand.

In this study, we expect that at least three kinds of factors may influence the severity assessments of the professionals: the societal context, including cultural traditions, institutions and media information about drugrelated problems; group level factors based on gender, age, profession, and personal addiction experiences; and such psychometric parameters as familiarity and the perceptions of controllability. Consequently, we hypothesize that socio-cultural factors (including the national "drug scene") will produce consistent differences between the responses of the French and Finnish respondents. We also expect that the differing occupational composition, together with the respondents' other socio-demographic characteristics, may modify their answers. Furthermore, we hypothesize that the prevalence of high-risk use in a country will affect the severity of the assessments, so that amphetamines are considered more risky in Finland than in France. Due to the higher prevalence of unproblematic cannabis use in France, we expect that the French professionals will regard it as less dangerous than the Finnish. 


\section{Methods}

\section{Questionnaires and Data Collection}

This study takes place in the international Images consortium exploring the ways in which different stakeholder groups perceive addictions in different cultural contexts. The questionnaire used for this study was originally developed by Jan Blomqvist (2009) in Sweden. The translation of the questions was conducted and double checked with due care, first for a comparative general population survey (Holma et al., 2011) and then for this survey. The questions covered eight substances and behaviors, but we concentrate only on three illicit drugs. The risk for individuals was queried by asking, "How high would you rate the risk of getting hooked after trying drug $\mathrm{x}$ ?" The risk for society was queried by asking the participants to assess the severity of 15 common social problems (see Figure 1) on a scale from 1 to 10 . The use of cannabis and other drugs were included in the list with four other addictive behaviors and nine common societal problems.

After ethical authorization was received for the data collection, mailed surveys were conducted in Finland in 2007-2008 and in France in 2010, using translations of the same questionnaires. Random samples could not be drawn, as there are no general registers of all the addiction treatment providers and units in either country. However, professionals from major addiction treatment services and criminal sanction agencies were recruited from the more populated southern Finland (Koski-Jännes et al., 2012). In France, the questionnaires were distributed to addiction, alcohol and prevention centers throughout the whole country (Simmat-Durand \& Toutain, 2012). However, many of them were returned by the postal service as undeliverable, resulting in a rather low response rate in France: 34\%, compared with 51\% in Finland.

\section{Subjects}

Professionals working personally with addicts were included in the study (see Table 1). The participants in Finland $(n=520)$ were more often females, social workers or counsellors living in the capital area, with lower education and shorter experience in the field of addiction. Conversely, the participants in France $(n=472)$ were more often males, medical doctors, living in a city but not in the capital, with a high educational level and over five years in addiction treatments (Table 1). The main product which the respondents declared having a current or a previous dependence on was tobacco.

\section{Figure 1}

\section{Comparison of the median severity scores given to the different problems by country}

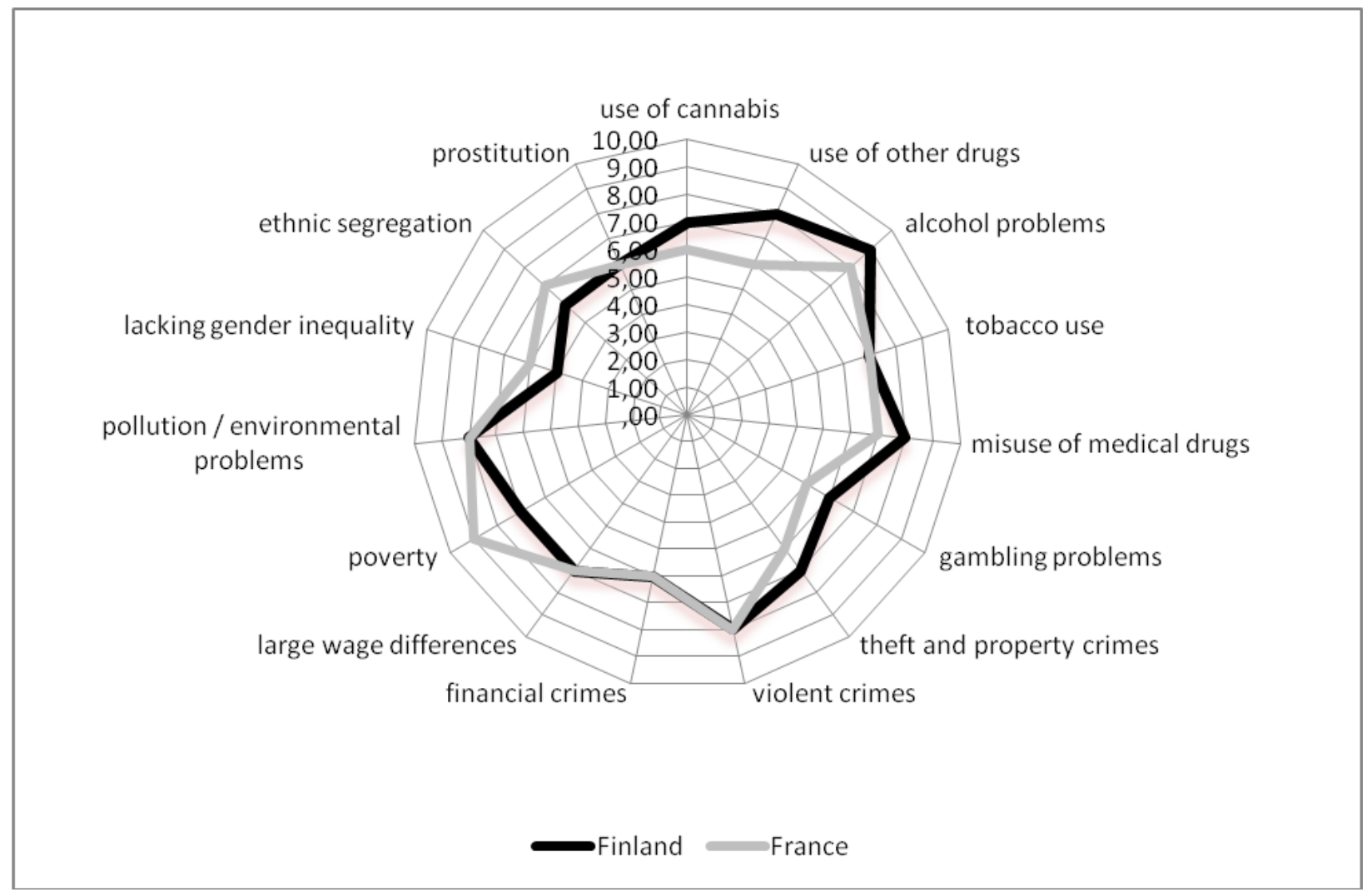


Table 1

Description of the professionals (\%) who answered the questionnaire, by country

\begin{tabular}{|c|c|c|}
\hline & $\begin{array}{c}\text { Finland } \\
(n=520)\end{array}$ & $\begin{array}{c}\text { France } \\
(n=472)\end{array}$ \\
\hline \multicolumn{3}{|l|}{ Gender*** } \\
\hline Male & 23.8 & 33.3 \\
\hline Female & 76.2 & 66.7 \\
\hline \multicolumn{3}{|l|}{ Residence*** } \\
\hline Capital & 51.4 & 29.2 \\
\hline Other city & 37.6 & 47.7 \\
\hline Rural area & 11.0 & 23.1 \\
\hline \multicolumn{3}{|l|}{ Birth cohort $^{\text {ns }}$} \\
\hline$<1960$ & 33.3 & 31.2 \\
\hline 1960-1979 & 55.9 & 57.1 \\
\hline$>1979$ & 10.8 & 11.6 \\
\hline \multicolumn{3}{|l|}{ Experience with addicts ${ }^{* * *}$} \\
\hline Up to 5 years & 39.7 & 30.6 \\
\hline More than 5 years & 60.3 & 69.4 \\
\hline \multicolumn{3}{|l|}{ Basic education $* * *$} \\
\hline Less than 12 years & 34.0 & 0.4 \\
\hline 12 years or more & 66.0 & 99.6 \\
\hline \multicolumn{3}{|l|}{ Profession $* * *$} \\
\hline Unit director & 10.6 & 11.1 \\
\hline Medical doctor & 2.5 & 34.8 \\
\hline Health care professional & 31.5 & 17.5 \\
\hline Social worker/counselor & 50.4 & 36.7 \\
\hline Other & 5.0 & 0 \\
\hline \multicolumn{3}{|l|}{ Dependence on tobacco ${ }^{\text {ns }}$} \\
\hline Never & 46.5 & 46.1 \\
\hline Now or in the past & 53.5 & 53.9 \\
\hline \multicolumn{3}{|l|}{ Dependence on cannabis ${ }^{\mathrm{ns}}$} \\
\hline Never & 97.3 & 96.3 \\
\hline Now or in the past & 2.7 & 3.7 \\
\hline \multicolumn{3}{|l|}{ Dependence on opiates $^{\text {ns }}$} \\
\hline Never & 98.8 & 98.7 \\
\hline Now or in the past & 1.2 & 1.3 \\
\hline
\end{tabular}

*** $p<0.001 ; n s=$ non significant

\section{Data Analysis}

The data were computerized separately in each country and then merged, and the coding checked according to the specificities of each country. All the statistical analyses were done by SPSS19. The dependent variables were the responses to the two main questions and the independent variables were the background data of the respondents. The responses were compared using $X^{2}$-statistics, comparisons of means and medians. Adjusted logistic regression analysis was used on the dichotomized response alternatives. Factor analysis with principal component analysis and varimax rotation, was used to find more basic dimensions behind the responses to societal problems. The level of significance was $p<.05$.

\section{Results}

\section{Individual Risk of Dependence}

The individual risk of getting hooked on cannabis was estimated as rather or very high by $37 \%$ of the French and $54 \%$ of the Finnish professionals (Table 2). When the background variables were controlled by logistic regression analyses (see Table 3), the country difference remained; the French and the more educated participants were half as likely to estimate the risk of using cannabis as high, while living in cities other than the capital doubled the probability (See Table 3).

The views on heroin were more similar: $95 \%$ of the French versus $90 \%$ of the Finnish professionals assessed the risk of dependence as rather or very high. Controlling the demographic variables (Table 3), the French were twice as 
Table 2

The responses (\%) to the risk of getting hooked after trying, by country

\begin{tabular}{|c|c|c|c|c|c|}
\hline & & $\begin{array}{l}\text { Finland } \\
N=520\end{array}$ & $\begin{array}{c}\text { France } \\
N=472\end{array}$ & $\begin{array}{c}\text { Total } \\
N=992\end{array}$ & $p$ \\
\hline \multicolumn{6}{|c|}{ Risk of getting hooked on cannabis } \\
\hline$\checkmark$ & None or very low & 6.8 & 7.1 & 6.9 & $<0.001$ \\
\hline$\checkmark$ & Rather low & 39.6 & 55.6 & 46.9 & \\
\hline$\checkmark$ & Rather high & 42.1 & 30.7 & 36.8 & \\
\hline & Very high & 11.5 & 6.6 & 9.3 & \\
\hline \multicolumn{3}{|c|}{ Risk of dependence on amphetamines } & & & $<0.001$ \\
\hline & None or very low & 3.7 & 7.1 & 5.2 & \\
\hline$\checkmark$ & Rather low & 11.3 & 36.3 & 22.4 & \\
\hline$\checkmark$ & Rather high & 43.9 & 42.6 & 43.3 & \\
\hline & Very high & 41.1 & 14.1 & 29.1 & \\
\hline \multicolumn{3}{|c|}{ Risk of dependence on heroin or other opiates } & & & 0.004 \\
\hline$\checkmark$ & None or very low & 2.9 & 2.3 & 2.6 & \\
\hline$\checkmark$ & Rather low & 7.2 & 2.5 & 5.1 & \\
\hline$\checkmark$ & Rather high & 28.9 & 26.2 & 27.7 & \\
\hline$\checkmark$ & Very high & 60.9 & 69.0 & 64.6 & \\
\hline
\end{tabular}

Table 3

Adjusted logistic regression, odds ratio for considering the risk of cannabis addiction as "rather or very high"

\begin{tabular}{|c|c|c|c|c|c|}
\hline & & OR & \multicolumn{2}{|c|}{ CI 95\% } & $p$ \\
\hline \multicolumn{6}{|c|}{ Considering the risk of cannabis addiction as "rather or very high" } \\
\hline \multicolumn{6}{|c|}{ Gender } \\
\hline$\checkmark$ & Male (ref) & 1 & & & \\
\hline$\checkmark$ & Female & 1.309 & .962 & 1.780 & .087 \\
\hline \multicolumn{6}{|c|}{ Country } \\
\hline$\checkmark$ & Finland (ref) & 1 & & & \\
\hline & France & .592 & .423 & .829 & .002 \\
\hline \multicolumn{6}{|c|}{ Basic education } \\
\hline$\checkmark$ & < 12 years (ref) & 1 & & & \\
\hline$\checkmark$ & 12 years and more & .549 & .375 & .804 & .002 \\
\hline \multicolumn{6}{|c|}{ Residence } \\
\hline$\checkmark$ & Capital (ref) & 1 & & & \\
\hline$\checkmark$ & Other cities & 1.970 & 1.316 & 2.948 & .001 \\
\hline$\checkmark$ & Rural areas & 1.308 & .888 & 1.926 & .174 \\
\hline \multicolumn{6}{|c|}{ Professions } \\
\hline$\checkmark$ & Unit director (ref) & 1 & & & \\
\hline$\checkmark$ & Medical doctor & .671 & .270 & 1.671 & .392 \\
\hline$\checkmark$ & Health care professional & .677 & .272 & 1.686 & .402 \\
\hline$\checkmark$ & Social worker. counselor & .528 & .224 & 1.243 & .144 \\
\hline$\checkmark$ & Other & .563 & .243 & 1.303 & .180 \\
\hline \multicolumn{6}{|c|}{ Considering the risk of heroin addiction as "rather or very high" } \\
\hline \multicolumn{6}{|c|}{ Gender } \\
\hline$\checkmark$ & Male (ref) & 1 & & & \\
\hline$\checkmark$ & Female & .757 & .409 & 1.401 & .376 \\
\hline \multicolumn{6}{|c|}{ Country } \\
\hline$\checkmark$ & Finland (ref) & 1 & & & \\
\hline$\checkmark$ & France & 2.033 & 1.093 & 3.781 & .025 \\
\hline \multicolumn{6}{|c|}{ Basic education } \\
\hline$\checkmark$ & $<12$ years (ref) & 1 & & & \\
\hline$\checkmark$ & 12 years and more & .338 & .154 & .742 & .007 \\
\hline
\end{tabular}




\begin{tabular}{|c|c|c|c|c|c|}
\hline & & OR & \multicolumn{2}{|c|}{ CI 95\% } & $\underline{p}$ \\
\hline \multicolumn{6}{|c|}{ Residence } \\
\hline$\checkmark$ & Capital (ref) & 1 & & & \\
\hline$\checkmark$ & Other cities & 2.860 & 1.162 & 7.037 & .022 \\
\hline$\checkmark$ & Rural area & 1.351 & .530 & 3.444 & .529 \\
\hline \multicolumn{6}{|c|}{ Professions } \\
\hline$\checkmark$ & Unit director (ref) & 1 & & & \\
\hline$\checkmark$ & Medical doctor & 1.615 & .310 & 8.422 & .570 \\
\hline$\checkmark$ & Health care professional & .784 & .137 & 4.488 & .785 \\
\hline$\checkmark$ & Social worker. counselor & 1.297 & .276 & 6.091 & .741 \\
\hline$\checkmark$ & Other & 1.694 & .373 & 7.685 & .495 \\
\hline \multicolumn{6}{|c|}{ Considering the risk of amphetamine addiction as "rather or very high" } \\
\hline \multicolumn{6}{|c|}{ Gender } \\
\hline$\checkmark$ & Male (ref) & 1 & & & \\
\hline$\checkmark$ & Female & 1.070 & .751 & 1.524 & .710 \\
\hline \multicolumn{6}{|c|}{ Country } \\
\hline$\checkmark$ & Finland (ref) & 1 & & & \\
\hline$\checkmark$ & France & .286 & .194 & .420 & .000 \\
\hline \multicolumn{6}{|c|}{ Basic education } \\
\hline$\checkmark$ & $<12$ years (ref) & 1 & & & \\
\hline$\checkmark$ & 12 years and more & .282 & .144 & .552 & .000 \\
\hline \multicolumn{6}{|c|}{ Residence } \\
\hline$\checkmark$ & Capital (ref) & 1 & & & \\
\hline$\checkmark$ & Other cities & 1.830 & 1.141 & 2.935 & .012 \\
\hline$\checkmark$ & Rural area & 1.137 & .719 & 1.798 & .583 \\
\hline \multicolumn{6}{|c|}{ Professions } \\
\hline$\checkmark$ & Unit director (ref) & 1 & & & \\
\hline$\checkmark$ & Medical doctor & 2.100 & .445 & 9.902 & .349 \\
\hline$\checkmark$ & Health care professional & 2.641 & .573 & 12.172 & .213 \\
\hline$\checkmark$ & Social worker. counselor & 2.477 & .551 & 11.140 & .237 \\
\hline$\checkmark$ & Other & 2.544 & .574 & 11.283 & .219 \\
\hline
\end{tabular}

prone to assess the risk of heroin as high. Higher basic education reduced the fear of heroin dependence, and living in cities other than the capital increased it

The Finnish respondents emphasized the addiction potential of amphetamines much more than the French did: $85 \%$ of the Finns, versus $57 \%$ of the French, estimated the risk as rather or very high. Controlling the background variables, the French and the more educated were three times less likely to estimate this risk as high, while living in cities other than the capital doubled the probability, as did belonging to professions other than unit directors (Table 3).

\section{Risk to Society}

When asked to assess the severity of 15 common societal problems (see Figure 1) on a scale from 1 to 10 , cannabis use was given an average of 6.65 by the Finns and 6.17 by the French $(t=3.399 ; p=.001)$, but the median values were 7 and 6 , respectively. The use of other (i.e., hard) drugs was considered a more severe problem in both countries, clearly more so in Finland, where it was given an average of 7.79, as opposed to 6.42 in France $(t=10.530 ; p$ $<.001$ ); the respective medians were 8 and 6 . So, both cannabis and hard drugs worried the Finnish professionals more than the French. In fact, the former regarded all addictive behaviors, except smoking, as more severe societal problems than did the latter.
In terms of means, the Finns ranked alcohol problems as their worst societal problem; "hard" drugs came second and the use of cannabis ninth. The French considered poverty their most serious societal issue, alcohol problems second, "hard" drugs ninth, and cannabis twelfth. When countries, genders, basic educations, residences and professions were controlled, the Finns attributed a score above six to the use of cannabis 1.5 times more often $(O R=1.500$; $95 \% \mathrm{CI}=$ 1.057-2.127; $p=0.023)$, whereas men did it less often than women $(O R=.571 ; 95 \% \mathrm{CI}=.418-.780 ; p<.001)$. For other drugs, the Finns attributed a score above six three times more often $(O R=3.41 ; 95 \%$ CI $=2.193-5.090 ; p<$ $.001)$.

To uncover more basic dimensions behind the responses on societal problems, the answers were factor analyzed by country (see Table 4). The responses loaded on two factors in Finland and three factors in France. Together, they explained $55.2 \%$ and $61.8 \%$ of the response variance, respectively. In Finland, all addictive behaviors got high loadings on the first factor including criminality issues. It was interpreted to reflect perceived "threats to safety," whereas the second factor received high loadings from equality issues. In France, the first factor included only addictive behaviors, the second covered equality issues, and the third factor received high loadings from criminal behavior and pollution. The Finns thus perceived addictive behaviors more as transgressions of law than as special problems of individuals. 
Table 4

Factors explaining gravity assessments of societal problems in Finland and France: Principal component analysis with Varimax rotation

\begin{tabular}{|c|c|c|c|c|c|}
\hline & \multicolumn{2}{|c|}{ Finland } & \multicolumn{3}{|c|}{ France } \\
\hline & 1 & 2 & 1 & 2 & 3 \\
\hline Alcohol problems & .532 & & .662 & & \\
\hline Theft and property crimes & .751 & & & & .815 \\
\hline Pollution / environmental problems & & .534 & & .460 & .545 \\
\hline Use of cannabis & .837 & & .792 & & \\
\hline Use of other drugs & .843 & & .765 & & \\
\hline Gender inequality & & .688 & & .707 & \\
\hline Tobacco use & .537 & & .723 & & \\
\hline Violent crimes & .660 & .384 & & & 639 \\
\hline Large wage differences & & .815 & & .781 & \\
\hline Prostitution & .507 & .566 & .586 & .424 & \\
\hline Poverty & & .788 & & .739 & \\
\hline Gambling problems & .613 & .447 & .696 & & \\
\hline Ethnic segregation & & .712 & & .834 & \\
\hline Misuse of medical drugs & .732 & & .757 & & \\
\hline Financial crimes & .399 & .614 & & .649 & \\
\hline$\%$ of variance explained & 43.3 & 11.9 & 40.9 & 13.7 & 7.1 \\
\hline Cumulative variance \% & & 55.2 & & & 61.8 \\
\hline
\end{tabular}

\section{Discussion}

Clear differences appeared between the views of the French and Finnish addiction treatment professionals on the dangerousness of heroin, amphetamines and cannabis. As hypothesized, these differences did not disappear when the respondents' other background variables were controlled for. It is particularly interesting that the different professional composition of treatment providers did not modify the responses. So, although the medical profession is much more dominant in France, while in Finland most treatment providers are social workers and counselors, the observed differences could not be explained by the respondents' professions. Possible explanations could be sought from the governing cultural images of illicit drugs in these countries (Koski-Jännes et al., 2012; Samuelsson et al., 2013).

Level of education and place of residence also affected responses. Those with higher basic education were significantly more prone to belittle the addiction potential of these drugs, even heroin. Small-town dwellers tended to stress the drugs' addiction potential more than those in the capital area.

The Finns were more concerned about cannabis and other drugs, and about addictive behaviors in general. This was also shown in the factor analysis, where they linked addictive behaviors with other illegal behaviors on the "threats to safety" factor, as opposed to the second "equality" factor. A similar two-factor solution appeared in the corresponding general population survey in Finland (Hirschovits-Gerz, 2008; Holma et al., 2011). In France, conversely, the same questions produced a three-factor solution with clearly different groups of items: addictions, equality issues, and criminal behaviors. So, although cannabis, heroin and amphetamines are illicit drugs in France too, their use, as well as most other addictive behaviors, was not associated with criminality.

The societal context and the different "drug scenes" also appeared to modify the responses. Both groups displayed a high level of concern about heroin, but as expected, the professionals in France were less worried about amphetamines than were their colleagues in Finland, where this substance is much more commonly used and injected (EMCDDA, 2011). The French professionals also assessed the individual and societal risks of cannabis dependence as lower. This could be explained by the wide use of cannabis and its image as a recreational drug in France. So although a much higher percentage of clients seeking treatment in France are cannabis users, its addiction potential is seen as lower there than in Finland. Cunningham et al. (2012) also show with population surveys that Finns and the Swedes are more worried about cannabis than are Canadians. This difference could be due to the long Nordic tradition of regarding alcohol and drug abuse as social problems (Palm, 2004). Conversely, in France, these problems are considered individual matters requiring a more medical approach (Bergeron, 1999).

Opinions on drugs partly depend on how close the respondents are to the products. The participants were only asked about their personal dependence experiences, and not about their use of, or experiments with, these products. Due to the low level of dependence declared (except for tobacco), we were unable to determine its influence on their views concerning risks, as done in other studies (Berger \& Courty, 2007; Galand \& Salès-Wuillemain, 2009). In our 
data, the respondents' duration of work experience with addicts did not modify the way risks were assessed.

The lack of random samples and the low response rates in France could be regarded as limitations of this study. Some information was probably also lost in dichotomizing the response variables for logistic regression analyses.

\section{Conclusions}

This study shows that societal context, level of education and place of residence affect the views of addiction treatment professionals more than their professions do. In France and Finland, views on heroin converged with expert assessments. As expected, the higher rates of high-risk use of amphetamines in Finland increased perception of its dangers there, and the widespread recreational use of cannabis in France reduced perceptions of its harmfulness. Paradoxically, this may result in medically oriented French professionals having a reduced interest in caring for cannabis users, although almost half of their new clients declare cannabis as their primary drug.

\section{Acknowledgements}

We thank Marjo Pennonen for collecting the Finnish data and the anonymous reviewers for their valuable suggestions on how to improve the manuscript.

\section{References}

Berger, D., \& Courty, P. (2007). Représentations du cannabis des futurs acteurs de prévention en formation [Representations of cannabis from the future actors of prevention in training]. Santé Publique, 19, 386-399.

Bergeron, H. (1999). L'Etat et la toxicomanie. Histoire d'une singularité française [The State and the drug addiction. History of a singularity french]. Paris, France: P.U.F.

Blomqvist, J. (2009). What is the worst thing you could get hooked on? Popular images on addiction problems in contemporary Sweden. NAT, 26, 373-398.

Blomqvist, J., Koski-Jännes, A., \& Cunningham, J. A. (2014). How should substance use problems be handled? Popular views in Sweden, Finland, and Canada. Drugs and Alcohol Today, 14(1), 19-30.

Bourgain, C., Falissard, B., Blecha Lisa, Benyamina, A., Karila, L., \& Reynaud, M. (2012). A damage/benefit evaluation of addictive product use. Addiction, 107, 441-450.

Brener, L., von Hippel, W., von Hippel, C., Resnick, I., \& Treolar, C. (2010). Perceptions of discriminatory treatment by staff as predictor of drug treatment completion: Utility of a mixed methods approach. Drug and Alcohol Review, 29, 491-497.

Christie, N., \& Bruun, K. (1986). Hyvä vihollinen. Huumausainepolitiikka Pohjolassa. (Good enemy. Drug policy in Nordic countries). Espoo: Weilin+Göös.
De los Reyes, C. M. (2002). Overcoming pessimism about treatment of addictions. JAMA, 287, 1857.

Douglas, M., \& Wildavsky, A. (1982). Risk and culture. An essay on the selection of technological and environmental danger. Berkeley, CA, United States: University of California Press.

EMCDDA. (2011). Amphetamines, ecstasy, hallucinogens, GHB and ketamine Annual Report 2011. The state of drug problem in Europe. European Monitoring Center on Drugs and Drug Addiction.

EMCDDA. (2012). Countries profile. from http://emcdda. europa.eu/publications/country-overviews/fr/datasheet

Ezzati, M., Lopez, A. D., Rodgers, A., Vander Hoorn, S., Murray, C. J. L., \& Comparative Risk Assessment Collaborating Group (2002). Selected major risks factors and global and regional burden of disease. Lancet, 360, 1347-1360.

Galand, C., \& Salès-Wuillemain, E. (2009). La représentation des drogues chez les étudiants en psychologie : effets des pratiques de consommation et influence de l'entourage [The representation of drugs among students in psychology: Effects of consumption practices and influence of the entourage]. Les Cahiers Internationaux de Psychologie Sociale, 84, 125-152.

Grassman, R., \& Weisner, C. (2005). Community providers views on alcohol problems and drug problems. Journal of Social Work Practice in Addictions, 5(4), 101-115.

Hirschovits-Gertz, T. (2013). How Finns perceive the obstacles to recovery from various addictions Nordic Studies on Alcohol and Drugs, 1-2(30), 87-104.

Hirschovits-Gerz, T. (2008). Suomalaisten käsityksiä riippuvuuksista - sukupuolen, iän sekä yhteiskunnallisen todellisuuden vaikutuksia mielikuviin. (The influence of gender, age and societal reality on the views of Finns on addictions). (Master's thesis), University of Tampere.

Hirschovits-Gerz, T., Holma, K., Koski-Jännes, A., Raitasalo, K., Blomqvist, J., Pervova, I., \& Cunningham, J. A. (2011). Is there something peculiar about Finnish views on alcohol addiction? - A crosscultural comparison between four Nordic populations. Research on Finnish Society, 4, 41-54.

Holma, K., Koski-Jännes, A., Raitasalo, K., Blomqvist, J., Pervova, I., \& Cunningham, J. A. (2011). Perceptions of addictions as societal problems in Canada, Sweden, Finland and St. Petersburg, Russia. European Addiction Research, 17, 106-112.

Joffe, H. (2003). Risk: From perception to social representation. British Journal of Social Psychology, 42, 55-73.

Koski-Jännes, A., Hirschovits-Gerz, T., \& Pennonen, M. (2012). Population, professional, and client support for different models of managing addictive behaviors. Substance Use \& Misuse, 47(3), 296-308.

Luquiens, A., Reynaud, M., Aubin, H.-J., Talon, C., \& Bourgain, C. (2013). Dommages et bénéfices associés aux substances addictives. Analyse quantitative de leur perception en population générale. Spécificités parisiennes et franciliennes [Damages and profits associated with addictive substances. Quantitative 
analysis of their perception in the general population. Specificities and parisian ÃŽLE]. Alcoologie et Addictologie, 35(3), 233-245.

Moscovici, S. (1988). Notes towards a description of social representations. European Journal of Social Psychology, 18(3), 211-250.

Nutt, D., King, L. A., \& Phillips, L. D. (2010). Drug harms in the UK: A multicriteria decision anlysis. Lancet, 376, 1558-1565.

Nutt, D., King, L. A., Saullsbury, W., \& Blakemore, C. (2007). Development of a rational scale to assess the harm of drugs of potential misuse. Lancet, 369, 10471053.

Orford, J., \& McCartney, J. (1990). Is excessive gambling seen as a form of dependence? Evidence from the community and the clinic. Journal of Gambling Studies, 6, 139-152.

Palm, J. (2004). The nature of and responsibility for alcohol and drug problems: views among treatment staff. Addiction Research \& Theory, 12(5), 413-431.

Pennonen, M., \& Koski-Jännes, A. (2010). Päihdealan ammattilaisten käsityksiä anineriippuvuuksista [Views of substance abuse professionals on various substance dependencies]. Janus, 18, 208-224.

Room, R. (2006). The dangerousness of drugs. Addiction, 101, 166-168.

Samuelsson, E., Blomqvist, J., \& Christophs, I. (2013). Addiction and recovery: Perceptions among professionals in the Swedish treatment system. Nordic Studies on Alcohol and Drugs, 2013(30), 51-66.

Simmat-Durand, L., \& Toutain, S. (2012). Quels modèles des addictions et de leurs traitements chez les professionnels des centres de soins en France [What models of addictions and their treatments among professionals in the care centers in France]. Alcoologie et Addictologie, 34(4), 289-298.

Slovic, P. (1987). Perception of risk. Science, 236, 280 285.

Tversky, A., \& Kahneman, D. (1974). Judgment under uncertainty: Heuristics and biases. Science, 185(4157), 1124-1131.

UNODC. (2012). World Drug Report: United Nations Office on Drug and Crime.

van Amsterdam, J., Opperhuizen, A., Koeter, M., \& van den Brink, W. (2010). Ranking the harm of alcohol, tobacco and illicit drugs for the individual and the population. European Addiction Research, 16, 202207.

Wilkinson, I. (2001). Social theories of risk perception: At once indispensable and insufficient. Current Sociology, 49(1), 1-22. 